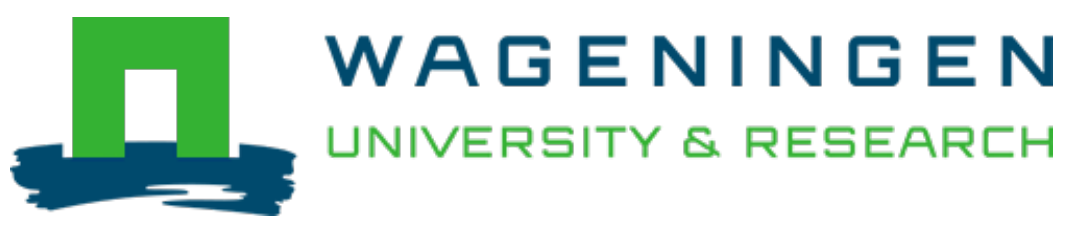

\title{
Identifying and managing conflicts between forest conservation and other human interests in Europe
}

Forest Policy and Economics

Niemela, J.; Young, J.; Alard, D.; Askasibar, M.; Henle, K. et al

https://doi.org/10.1016/j.forpol.2004.04.005

This article is made publicly available in the institutional repository of Wageningen University and Research, under the terms of article $25 \mathrm{fa}$ of the Dutch Copyright Act, also known as the Amendment Taverne. This has been done with explicit consent by the author.

Article 25 fa states that the author of a short scientific work funded either wholly or partially by Dutch public funds is entitled to make that work publicly available for no consideration following a reasonable period of time after the work was first published, provided that clear reference is made to the source of the first publication of the work.

This publication is distributed under The Association of Universities in the Netherlands (VSNU) 'Article $25 \mathrm{fa}$ implementation' project. In this project research outputs of researchers employed by Dutch Universities that comply with the legal requirements of Article $25 \mathrm{fa}$ of the Dutch Copyright Act are distributed online and free of cost or other barriers in institutional repositories. Research outputs are distributed six months after their first online publication in the original published version and with proper attribution to the source of the original publication.

You are permitted to download and use the publication for personal purposes. All rights remain with the author(s) and / or copyright owner(s) of this work. Any use of the publication or parts of it other than authorised under article $25 \mathrm{fa}$ of the Dutch Copyright act is prohibited. Wageningen University \& Research and the author(s) of this publication shall not be held responsible or liable for any damages resulting from your (re)use of this publication.

For questions regarding the public availability of this article please contact openscience.library@wur.nl 


\title{
Forest Policy
}

and

Economics

\section{Identifying, managing and monitoring conflicts between forest biodiversity conservation and other human interests in Europe}

\author{
Jari Niemeläa,*, Juliette Young ${ }^{\mathrm{b}}$, Didier Alard ${ }^{\mathrm{c}}$, Miren Askasibar ${ }^{\mathrm{d}}$, Klaus Henle ${ }^{\mathrm{e}}$, \\ Richard Johnson $^{\mathrm{f}}$, Mikko Kurttila ${ }^{\mathrm{g}}$, Tor-Björn Larsson ${ }^{\mathrm{h}}$, Simone Matouch ${ }^{\mathrm{i}}$, \\ Peter Nowicki ${ }^{\mathrm{j}}$, Rosa Paiva ${ }^{\mathrm{k}}$, Luigi Portoghesi ${ }^{1}$, René Smulders ${ }^{\mathrm{m}}$, \\ Alan Stevenson ${ }^{\mathrm{n}}$, Urmas Tartes ${ }^{\mathrm{o}}$, Allan Watt $^{\mathrm{b}}$ \\ ${ }^{\mathrm{a}}$ Department of Biological and Environmental Sciences, Faculty of Biosciences, P.O. Box 65, \\ FIN-00014 University of Helsinki, Helsinki, Finland \\ ${ }^{\mathrm{b}}$ Centre for Ecology and Hydrology, Hill of Brathens, Banchory, AB31 4BW UK \\ ${ }^{\mathrm{c}}$ University of Rouen Ecology Lab, UPRES-EA 1293 Boulevard de Broglie, 76821 Mont Saint Aignan, France \\ ${ }^{\mathrm{d}}$ PAISAIA, Agirre Miramon 8, 20002 Donostia, San Sebastian, Spain \\ ${ }^{\mathrm{e}}$ Department of Conservation Biology, UFZ Leipzig-Halle GmbH, Permoserstrasse 15, D-04318 Leipzig, Germany \\ ${ }_{\mathrm{f}}^{\mathrm{f}}$ epartment of Environmental Assessment, Swedish University of Agricultural Sciences, P.O. Box 7050, Vallvägen 3, Uppsala, Sweden \\ ${ }^{\mathrm{g}}$ Finnish Forest Research Institute, Joensuu Research Centre, P.O. Box 68, FIN-80101 Joensuu, Finland \\ ${ }^{\mathrm{h}}$ European Environment Agency, Kongens Nytorv 6, DK-1050 Copenhagen K, Denmark \\ ${ }^{\mathrm{i}} A R G E$ Naturschutzforschung und angewandte Vegetationsökologie, Österreichisches Netzwerk Umweltforschung, \\ Netzknoten, Biodiversität: Theobaldgasse 16/4, A-1060 Wien, Austria \\ ${ }^{\mathrm{j}}$ CEH/BioForum, Fons v.d. Heydenstraat 57, NL-5534 AT Netersel, The Netherlands \\ ${ }^{\mathrm{k}}$ DCEA-FCT, Universidade Nova de Lisboa, PT-2825-516 Campus de Caparica, Portugal \\ ${ }^{1}$ Dipartimento di Scienze dell'Ambiente Forestale e delle sue Risorso (DISAFRI), Università della Tuscia, \\ Via $S$. Camillo de Lellis, 01100 Viterbo, Italy \\ ${ }^{\mathrm{m}}$ Plant Research International, Wageningen UR, P.O. Box 16, NL-6700 AA Wageningen, The Netherlands \\ ${ }^{\mathrm{n}}$ Forest Enterprise Agency, Forestry Commission, Edinburgh, EH12 7 AT UK \\ ${ }^{\circ}$ Institute of Zoology and Botany, Estonian Agricultural University, Riia 181, Tartu, 51014 Estonia
}

Received 13 October 2003; received in revised form 19 March 2004; accepted 20 April 2004

\begin{abstract}
In this paper, circumstances where various human activities and interests clash with the conservation of forest biodiversity are examined, with particular focus on the drivers behind the conflicts. After identifying past and current human-related threats potentially leading to conflicts in forests, the paper will focus on conflict management and monitoring, with an emphasis on inclusionary stakeholder networks and a range of approaches towards sustainable land use. Three dimensions of conflicts are
\end{abstract}

\footnotetext{
* Corresponding author. Tel.: +35891915 7849; fax: +358 919157788.

E-mail address: jari.niemela@helsinki.fi (J. Niemelä).
} 
examined: substance ('how things are'), procedure ('how things are done'), and relationships ('how people behave'). These relations will relate to three conflict management approaches: (1) technical, which may contribute to reduce or solve the conflict acting on the 'substance' dimension, (2) political, which may influence the 'procedure' dimension of the conflict establishing principles or rules, and (3) cultural, which may affect the 'relationship' dimension of the conflict. Finally, a general model of adaptive conflict management emphasising communication among the parties and a participatory approach that involves monitoring of the conflict resolution outcomes is proposed. The recognition that strong perceptions among stakeholders have the potential to aggravate conflicts is central to the concept of a inclusionary conflict management framework, improved communication between all stakeholders, and better awareness of the context of the conflicts is emphasised.

(C) 2004 Elsevier B.V. All rights reserved.

Keywords: Forest conflicts; Conflict management; Forest biodiversity

\section{Introduction}

Since the introduction of agriculture, the average rate of global deforestation has been estimated to be 0.25 million ha/year (Ball, 2001). Deforestation is a major problem in the tropics with over $7 \%$ of tropical forests (142 million ha) turned into "other land uses" between 1990 and 2000. However, in non-tropical areas, forested land increased somewhat, as $1 \%$ of non-forested land use classes were (re)converted to forests (FAO, 2001). Although forest land has increased in Europe, only 1.6\% of the 'natural' forests in Europe (excluding Russia) are protected (Larsson, 2001).

The dramatic forest losses in the tropics have resulted in conflicts between people in favour of forest clearing and those concerned about biodiversity loss. Although the situation is similar in some European countries, in most parts of Europe, however, forestrelated conflicts are due to changing demands concerning forests and forestry (Hellström and Reunala, 1995). Even re-forestation may be a source of conflict, if the existing biodiversity is considered more valuable than that of the new (often plantation) forest. Thus, there is a need to identify the drivers leading to disputes between human activities and the conservation of biodiversity, and to find methods to manage and monitor the conflicts.

The aim of this paper is to examine circumstances and cases where human activities and interests clash with the conservation of forest biodiversity, focussing primarily on the drivers behind the conflicts rather than the conflicts themselves. The term "conflict" used here will refer to situations where disputes drift outside settled social mechanisms (Hellström, 2001, p. 12). The first part of the paper will identify past and current human-related threats to forest biodiversity, which could lead to conflicts. In the second part, we will identify a generic approach to conflict management and monitoring, with an emphasis on inclusionary stakeholder participation, and a range of approaches towards sustainable land use. It is, however, acknowledged that all conflicts have to be dealt with in a unique manner, according to the species, habitats, human culture, and considering the socioeconomic characteristics of the region involved (Hellström, 2001).

This paper is a contribution from the EU-funded 'Bioforum' project (EVK2-CT-1999-2006, www.nbu. ac.uk/bioforum) with the aim to assess conflicts between the conservation of biodiversity and economic development, particularly within forests, grasslands, uplands (including alpine regions), inland wetlands, and agricultural landscapes in Europe. Furthermore, the project will provide a forum for the dialogue between scientists and stakeholders concerned with biodiversity. In addition to reports on approaches to resolving conflict affecting biodiversity, the project will focus on the elaboration of operational principles for spatial planning relating to biodiversity, and on the use of biodiversity indicators and including recommendations for future research priorities.

\section{History and current trends in forest conflicts in Europe}

\subsection{A historical perspective on forest conflicts in Europe}

In Europe, forests and forestry have long been a battlefield for a variety of interests. Until the late 18th 
century, timber was a basic human requirement across Europe. In addition, woodlands were used for raising cattle and swine, and were places where the nobility enjoyed hunting. Forests also played a key role in the development, maintenance and projection of economic and military strength, and were cultural icons which symbolised status in society (Schama, 1996). All this resulted in conflicts between the competing priorities within society for different forms of land use, and the quantity and types of goods and services derived from forests. It also resulted in those who wielded power taking steps to secure their interest in and access to the forest resource. Nevertheless, land rules often recognised the need to implement laws aiming at a sustainable use of natural resources, and particularly forests, some of which reveal a profound understanding of forest ecosystem functions (Baeta-Neves, 1990).

In the 18th century, the demands placed on forests in Europe escalated due to population growth. Conflicts around land use change, mainly the expansion of pastureland for sheep farming, were particularly acute. Although achieved to a large extent at the cost of tillage land, the usurpation of the commons also played a part in this agricultural revolution and resulting peasant displacement and social unrest (Lipson, 1949). Concerns about wood shortage (Perlin, 1989) triggered forest management in Europe to increase productivity, control the rate and type of exploitation, and conserve the area of forest. Forest administrations were set up, and forest science began to improve forestry techniques (Matthews, 1989).

The industrial revolution reduced the status of wood as a locally utilised product. Nevertheless, wood remained important as an increasingly significant resource for industry. The practice of silviculture was also modified to take the demographic and social changes into account. The 19th and 20th centuries saw intensification of management and the establishment of plantations often comprising of non-local trees. Natural and man-made ecosystems were largely perceived as a source of products having a direct market value only, while indirect market values, nonmarket values, as well as ethic and aesthetic values were either not recognised or at the least, not quantified. This new position of man in control of nature rather than as a constituent part of the natural world was to give rise to major conflicts involving forests in the modern era of forestry.

The development described above consists of several parallel processes, with a wide variation in time and geographical scale. For example, conflicts between traditional land use (extensive grazing, collection of wood for fuel) and silviculture for industrial production is still ongoing in some parts of Europe (e.g. locally in southern and more widely in eastern/southeastern Europe).

\subsection{Emerging forest policy trends in Europe}

Although no world treaty on forests has yet been adopted, a number of international initiatives, including non-governmental and private sector ones, have been taken since the Rio Conference in 1992 (FAO, 2002). In Europe, several policy developments have had an impact on forest resource management, and thereby also on conflicts related to the various forest uses. The Ministerial Conference on the Protection of Forests in Europe (MCPFE) was launched in 1990 as a Pan-European cooperation addressing threats related to forests and forestry, and promoting the sustainable management of forests (Mayer, 2000). This process, now comprising around 40 European countries, is not only a forum for cooperation of ministers responsible for forests, but it also allows non-governmental and intergovernmental organisations to contribute with their knowledge and ideas.

The Treaties of the European Union make no provision for a comprehensive common forestry policy. The management, conservation and sustainable development of forests are, nevertheless, vital concerns of existing policies, such as the Common Agricultural Policy, rural development, environment, trade, internal market, research, industry, development cooperation, and is the subject of specific environmental issues such as the EU Biodiversity Strategy, Natura 2000, and the implementation of the Climate Change Convention (UNFCC). Accordingly, several directives and regulations have been established. Most recently, a new regulation "Forest Focus" has been proposed establishing an expanded community monitoring of forests and environmental interactions. This will include continued monitoring of forest condition in response to the UNECE Convention on LongRange Transboundary Air Pollution and information 
about forest fires, but also address new issues such as forest biodiversity. The Rio Conference also triggered efforts at forest law design and reform throughout the world, with some 90 countries enacting new laws or amending existing legislation on forests over the last decade (FAO, 2002).

The Convention on Biological Diversity (CBD) in 2001 requested all contracting parties to deliver a report on Forest Ecosystems. Furthermore, the CBD launched an expanded work programme on Forest Biological Diversity at its sixth Conference of the Parties (The Hague, 2002). The priorities suggested include (a) conservation, sustainable use and benefit sharing, (b) institutional and socioeconomic enabling environment and knowledge, and (c) assessment and monitoring. The second element, being directly related to this study, has three components: improved governance, determining causes for and addressing failures in policy, and improvement of the understanding of the value of forest biodiversity to humans. In addition to conventions and legislation, voluntary commitments to forest protection are becoming increasingly important (Tikka and Kauppi, 2003). Also, certification schemes for ecologically sensitive forestry practices are gaining importance.

Institutional changes, globalisation, the communication revolution, and societal and cultural changes are reflected in the type and intensity of forest conflicts. Thus, forests have become objects of various interests and interest groups having different views about forestry. Economic growth can be seen as the principal cause of the intensification of forestry, which has led to increased living standards and thus increased demand for recreational use of forests. On the other hand, the same economic growth caused changes in the forest environment that were considered detrimental to biodiversity (Larsson, 2001). Concomitantly, the increased societal importance of the environmental movement was at least partly fuelled by scientific reports on environmental problems. In industrialized countries, the process leading to intensified forest conflicts is intimately linked with social and cultural development with such phenomena as urbanization, continued industrialization and increased standard of living leading to changed values (Hellström and Reunala, 1995).

\section{Identification of conflicts}

\subsection{Issues leading to forest-related conflicts}

Since the 1950s, European forest conflicts have occurred because of three types of development: (1) intensification of forestry operations, (2) increasing recreational needs, and (3) the increased importance of the environmental movement (Hellström and Reunala, 1995). The intensification of forestry can manifest itself through: (a) overall changes in forest management (e.g. through changes in ownership structure, systems for transportation of wood to industry, changing of planning strategy, and suppression of natural forest fires), (b) changes in silvicultural systems (e.g. modified harvesting such as introducing clear-cutting, shortening of crop rotation times, introduction of exotic species and plantation forestry, installation and/or alteration of drainage systems, and use of fertilizers, pesticides and herbicides), and (c) introduction of new technologies (e.g. new machinery for timber harvesting and treatment of regeneration areas, and new types of forest roads) (Hellström and Reunala, 1995).

Policies pursued at local, regional or national scales may favour economic development and urbanization, agriculture, or grazing; all of which may clash with forest biodiversity conservation. In addition, changes in land ownership patterns and economy, such as those taking place in the eastern parts of Europe, may lead to conflicts with biodiversity conservation. A range of policies may also indirectly result in land use changes. For instance, depopulation of rural areas leads to abandonment of land, including forested land. This may lead to both positive and negative outcomes for biodiversity. One negative outcome is an increased risk of forest fires. In southern Europe (Spain, France, Greece, Italy, Portugal), the area burnt increased exponentially between 1970 and 2000 (Bilgili and Goldammer, 2001). The catastrophic fires in the summer of 2003 in southern Europe are an alarming example. In Portugal, for example, it has been estimated that as much as $11 \%$ (ca. $350000 \mathrm{ha}$ ) of the country's forests burned, including $14 \%$ of protected areas (R. Paiva, pers. communication). The economic and social consequences are significant, but are difficult to estimate. On the other hand, forest fires are disturbances that 
can maintain high biological diversity (Prodon et al., 1987; Trabaud and Prodon, 1993).

Another policy-related change is the increasing importance of management of natural resources at the watershed level. Issues here include avalanche control in mountainous areas and flood control. Measures to control avalanches or floods can clash with protection of forests, though flood and river management often advocate the protection and expansion of near natural, highly diverse floodplain forests since well-structured forests can reduce the flow velocity and the peaks of floods. Military training ranges and security areas may act as reservoirs for biodiversity, but may also act as barriers. Changes in political circumstances may alter the need and use for such sites.

Changes in society's view on forests, e.g. the increased concern for forest biodiversity, means that forest professionals now face discussions involving values and life-style, and the need to seek strategies that are acceptable for all stakeholders. The increased recreational and conservational needs, for instance, have led to demands on forests other than wood production. As a result, new groups of stakeholders including municipalities, NGOs, the media and local residents have become involved in decisions on forest management. In Finland, for instance, forest conflicts are partly caused - or at least aggravated - by the inability of forestry professionals to adapt their views and approaches to accommodate changes in the society (Hellström and Reunala, 1995). It is important to acknowledge at this stage that although forest conflicts globally are similar in nature, each society will have its own way of creating and managing conflicts (Hellström, 2001).

\subsection{Forest conflicts: theoretical considerations}

In this paper, we follow the theoretical framework outlined by Hellström (2001, pp. 15-16) that is based on ideas derived from (a) a holistic view on natural resources, (b) social constructionism, and (c) conflict regulation theory. We find this approach flexible enough to accommodate the different kinds of forest-related conflicts in Europe that we deal with in this paper. According to the holistic view natural resources are not only attributes of the physical environment, but attributes of the economic, political, social and cultural order as well (Hellström, 2001, p. 15). The second component of the framework, social constructionism, views social problems as dynamic and collectively defined. For instance, environmental issues cause a significant social reaction only when people collectively interpret such issues as serious problems. The third component, conflict regulation theories, attempts to produce a synthesis between consensus theories (stating that social conflicts are temporary disturbances) and conflict theories (stating that conflicts are inevitable and necessary for social change). Conflict management is usually based on the idea of regulating the conflict, and on the view that conflicts have a potentially positive role in social development (Hellström, 2001, p. 16).

One useful way of construing conflicts is to examine their components. According to Walker and Daniels (1997, p. 22) any conflict includes three interrelated dimensions: substance, procedure, and relations, and a conflict can be addressed through any of the three dimensions. Using this approach, we will define what these dimensions represent in a forestry situation, with specific attention to conflicts with biodiversity.

- Substance ('how things are') addresses the type and status of forest habitats concerned, e.g. natural versus planted forest, in other words, status of ecological processes versus type of management regimes or natural capital versus economic capital.

- Procedure ('how things are done') addresses forestry (and environmental) legislation policy, implementation, enforcement, strategy, planning, and implementation. It also includes the type and nature of stakeholder engagement.

- Relationships ('how people behave') address the culture of individuals, organisations and society, and how they interact with each other. For example, state forest services were often founded with a quasi-military, hierarchical management structure, whereas nature conservation organisations often have more flexible management structures and are usually reliant on the contribution of individuals. This difference may in itself cause conflicts between the two parties.

Based on these three dimensions of conflicts, we develop an understanding of how biodiversity-related conflicts arise in forestry. Conflicts in forests are 
Table 1

Examples of the contribution of various types of forest, uses of forest, forest ownerships and wider use of forests to the conflicts of the substance of the matter, process of management or decision-making and relationships between people and organisations

\begin{tabular}{|c|c|c|c|}
\hline & \multicolumn{3}{|c|}{ Contribution to the conflict from the dimension of } \\
\hline & Substance & Procedure & Relationship \\
\hline \multicolumn{4}{|l|}{ Type of forest } \\
\hline Old growth & $\begin{array}{l}\text { Protected for nature or } \\
\text { economic exploitation? }\end{array}$ & $\begin{array}{l}\text { Nature conservation } \\
\text { designation versus economic } \\
\text { opportunities }\end{array}$ & $\begin{array}{l}\text { Tree huggers versus tree loggers, } \\
\text { state or development company } \\
\text { versus local inhabitants }\end{array}$ \\
\hline Semi-natural woodland & $\begin{array}{l}\text { Restoration or economic } \\
\text { exploitation? }\end{array}$ & $\begin{array}{l}\text { Process of conducting } \\
\text { restoration measures }\end{array}$ & $\begin{array}{l}\text { Forest industry versus } \\
\text { environmental NGOs }\end{array}$ \\
\hline Plantations & $\begin{array}{l}\text { Space for nature, open habitat } \\
\text { or afforestation? }\end{array}$ & $\begin{array}{l}\text { Forest planning and } \\
\text { operational practice. Tree } \\
\text { farming versus multipurpose } \\
\text { forestry. Conversion of open } \\
\text { habitat to plantation }\end{array}$ & $\begin{array}{l}\text { Environmental NGOs versus } \\
\text { forest industry. Recreation versus } \\
\text { forest industry. Grazing versus } \\
\text { forest industry }\end{array}$ \\
\hline $\begin{array}{l}\text { Reconstructed native } \\
\text { forest }\end{array}$ & $\begin{array}{l}\text { Conflict with other land uses } \\
\text { with other biodiversity assets }\end{array}$ & Land use planning & Professional stereotypes \\
\hline \multicolumn{4}{|l|}{ Use of forest } \\
\hline Grazing & Clearance for grazing & Planning of "sustainable" grazing & Farmers versus environmentalists \\
\hline Hunting & $\begin{array}{l}\text { Site capacity and conflict } \\
\text { with recreation and tourism }\end{array}$ & Protection or licence to exploit & Hunters versus other recreants \\
\hline Tourism & Site capacity & Licences, zoning & $\begin{array}{l}\text { Tourism "industry" made } \\
\text { ecologically friendly, ecotourism... }\end{array}$ \\
\hline Recreation & Site capacity & Communication systems & $\begin{array}{l}\text { Getting people to act and behave } \\
\text { responsibly }\end{array}$ \\
\hline \multicolumn{4}{|l|}{ Wider land use } \\
\hline $\begin{array}{l}\text { Roads, infrastructure } \\
\text { and urbanisation }\end{array}$ & $\begin{array}{l}\text { Forest loss and } \\
\text { fragmentation }\end{array}$ & $\begin{array}{l}\text { Planning priorities for economic } \\
\text { development or nature conservation }\end{array}$ & $\begin{array}{l}\text { Regional connections } \\
\text { versus local recreation }\end{array}$ \\
\hline Climate mitigation & $\begin{array}{l}\text { Local ecosystem or } \\
\text { global benefit }\end{array}$ & $\begin{array}{l}\text { e.g. system of carbon sequestration } \\
\text { certificates }\end{array}$ & $\begin{array}{l}\text { Believers versus non-believers } \\
\text { of climate change }\end{array}$ \\
\hline
\end{tabular}

usually related to land uses that are incompatible with biodiversity maintenance (Table 1). These conflicts are often related to economic development in one way or another. For instance, in the case of harvesting versus recreation, the forest owner wants to gain economic benefits from his forest by harvesting trees, which conflicts with other kinds of values respected by the people using the forest for recreation purposes (Kajala and Warson, 1997). A few examples of how economic and policy drivers affect substance, process and relationships are given in Fig. 1.

The scale of conflicts is important. There are several spatial scales of conflicts ranging from local to the regional, national or even international conflicts

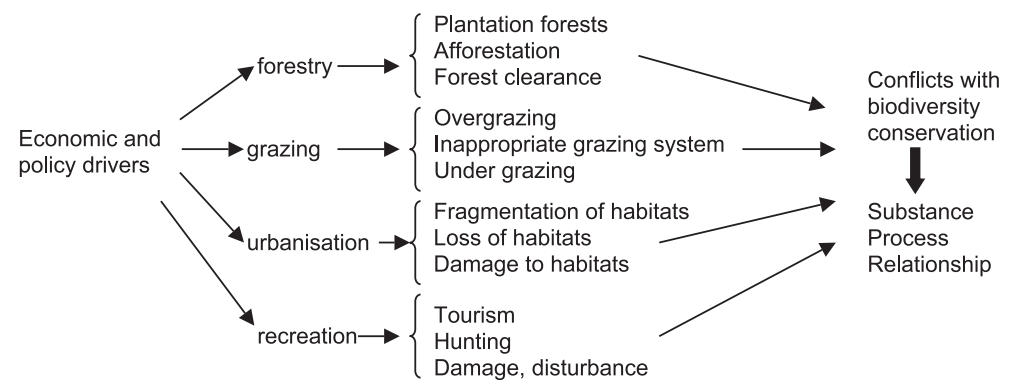

Fig. 1. Economic and policy drivers affecting substance, process and relationships of conflicts through various types of land uses. 
(Hellström, 2001). Similarly, there are several temporal scales, with conflicts manifesting themselves concomitantly with certain actions, or conflicts only become apparent years after a particular action took place. This 'time lag' is especially true in temperate-boreal forests where natural development of ecosystems operates at longer time frames than those with which politicians, society, and other land users are comfortable. Particularly at times of crisis and conflicts, managers and the public tend to focus on the fast variables, such as insect outbreaks or threats to an endangered species. These crises may be either natural events that are difficult to mitigate or symptoms of longer-term dynamics that could have been prevented by managing for slow variables (Folke et al., 2002). An understanding of the slowly changing biological and social variables that govern long-term dynamics is the key to the development of sound policies for conflict management and could help in the management of fast variables.

\section{Approaches in conflict management}

\subsection{Participatory procedures in conflict management}

Above, we have described how conflicts can arise and what their dimensions are. The next step is to develop conflict management strategies. We use the term conflict 'management' rather than 'resolution' because many conflicts are both complex and enduring, and may, therefore, never be completely resolved (Walker and Daniels, 1997, p. 21). However, often conflicts can be managed in such a way that the conflict situation does not become destructive.

We suggest that means to manage conflicts in relation to forests and biodiversity conservation, as identified in Tables 1 and 2, can be separated into three groups:

(a) Technical, which may contribute to reduce or solve the conflict acting on the 'substance' dimension, e.g. silvicultural guidelines, forest planning at or involving a local scale (watershed, community, and farm).

(b) Political, which may influence the 'procedure' dimension of the conflict establishing principles or rules (e.g. EU regulations, forest acts, national/regional forest and land use planning), providing financial compensation and incentives, and favouring stakeholder participation.

(c) Cultural, which may affect the 'relationship' dimension of the conflict. The aim should be to improve the ability of stakeholders to communicate with each other. The strategies to implement conflict resolution differ according to the attitude of people in different countries (Hellström, 2001): e.g. education policies aiming at improving the attitude of people to collaborate, and to acknowledge and respect the values of others; specific courses for forest managers to learn communication skills and techniques; advertising campaigns to make the public aware of the problems and to contrast lobbying actions.

It is often necessary to act on the three dimensions of the conflict at the same time, integrating more than one management method. Technical or scientific solutions alone can prove to be inapplicable. Similarly, participation alone cannot lead to feasible solutions without appropriate information and research provided by experts and local people (Walker and Daniels, 1997).

Once a conflict has arisen and its definition has been established by the relevant stakeholders (McCool et al., 2000), methods through which parties can collaborate and communicate are needed (Maguire and Boiney, 1994; Walker and Daniels, 1997; Mahanty and Russell, 2002). It is important to inform the local communities about the conflict resolution in progress, create awareness about the different interests and values at stake, and involve them in the process. This may be achieved by creating a forum for working in groups including the relevant stakeholders with regular meetings. An example is the Mountain Forests Tending Group in Switzerland where representatives of Federal Forest Services and NGOs meet to discuss how to reconcile the management of stands protecting against natural hazards (especially avalanches) with biodiversity conservation. Some effective agreements have been reached on how to restore stands after heavy windstorms. To let nature act without immediately harvesting and replanting the destroyed stands was accepted by foresters and local communities as a possible experimental strategy to regenerate the stands and improve biodiversity in the forests. The experimental stands are monitored in order to intervene in case the 
protective function was seriously compromised because of lack of natural regeneration. Financial compensation and incentives from the Swiss Forest Act for tending protective forests play a decisive role in implementing this strategy (Weber et al., 2002).

The above example demonstrates that an efficient way to manage conflicts is to involve the stakeholders in the planning process (see also Maguire and Boiney, 1994). Public participation activities can be viewed as conflict management regardless of whether the conflict is latent or enacted, as such participation can potentially prevent controversial situations from escalating into active disputes (Daniels and Walker, 1997). Public participation in planning situations is seen as a way to improve democratic decision-making, build citizenship and recreate civic space between the public and private sectors (Priscoli, 1997).

The challenges of participatory processes include selection of those who should participate and definition of who represents who. The definition of goals is another challenge as these may differ greatly between stakeholders and between forest owners Some owners emphasise the economic use, whereas others focus on maintaining biodiversity or want to manage their forests to maximise the production of particular resources, such as edible mushrooms (J. Niemelä, pers. observation). Some conflict management strategies (e.g. direct purchase by public sector or NGOs or compensation to forest owners, Table 2) tend to exclude certain uses of the forest. Those solutions are expensive and can be used only in a limited number of cases. Maintenance of biodiversity in such 'core' holdings could be supported by appropriate activities of owners of the neighbouring holdings. In the best case, the outcome is ecological efficiency with very small utility losses caused to the participating forest owners. As a consequence, many strategies require a participatory process based on an extended accountability system, which is particularly suitable when the non-monetary components of the social value of forests are important, and when users are numerous (Gamborg, 2002).

Table 2

Strategies and means that can be adopted to manage conflicts in relation to forests and biodiversity conservation

$\begin{array}{llll}\text { Intensive } & \text { Multi- } \\ \text { planting } & \text { functional } & \text { Options and guidelines for conflict resolution } \\ & \text { - Habitat networks and natural reserves }\end{array}$

Several types of forests are identified and options and guidelines for conflict resolution are given. Options and guidelines are divided into those dealing with substance, process or relationships of conflicts. The ticks indicate instances where the identified options and guidelines operate most efficiently. 
Implementation of strategies for forest planning presents a number of further challenges where smallscale private forestry practices are concerned (Kurttila, 2001; Tikka, 2003). A key issue is how to establish fairness in terms of economy and work load between landowners, when the interests of individual owners may conflict with those imposed by landscape considerations (Kurttila and Pukkala, 2003). Such situations are not easily handled even if similar economic conditions govern the decisions of all forest owners, if, for example, there are differences in size and type of habitats in different holdings (Carlsson et al., 1998). Voluntariness can encourage forest owners to participate in the planning process.

Local stakeholders' control over their own lives and equity between them, i.e. social sustainability, must be emphasised in resource management and utilisation on private lands (Tikka, 2003). This requires the forest plan to be acceptable among individual landowners, and demands cooperation between forest owners and planning experts. Variation between the objectives of forest owners is an important consideration and a largely unutilised opportunity in comprehensive planning for stakeholders' ecological management at the landscape scale. Such planning can be termed 'ecologically efficient regional planning' (Pukkala et al., 1997; Kurttila and Pukkala, 2003) and can be achieved by the integration of the different objectives of forest owners as additional criteria into optimal selection algorithms for biodiversity priority sites (c.f. Altmoos, 1999; Margules and Pressey, 2000).

This type of planning requires understanding of human behaviour, both spontaneous and strategic, in conflict situations. The value positions of the different stakeholders in the forest protection discourse may differ radically contributing to the creation of conflicts (Rantala and Primmer, 2003). Reaction to conflicts between biodiversity conservation and human impacts, policies or threatening situations can manifest itself in the creation of groups of people faced by the same threat. The issue is further complicated by the dynamism of the groups, with possible discord amongst stakeholders and shifting of stakeholders between groups.

Perceptions and prejudices of different groups can further exacerbate conflicts. Thus, conservationists are often perceived to propose management strategies that are incompatible with the local context, and tend to become so involved that they cannot communicate with the public or landowners without getting into dispute (Stoll-Kleemann, 2001a). Similarly, local forest owners are often perceived by conservationists as being incapable of understanding the importance of protecting wildlife and habitats, and putting up strong resistance to any proposed changes in traditional landuse practices. This may be because the local stakeholders feel that they have no 'ownership' in the matter and that their knowledge and rights count for nothing. This perceived or real lack of trust can intensify the conflict (Rantala and Primmer, 2003).

These strong perceptions and barriers have the potential to create or aggravate conflicts between biodiversity and economic development, leading to the idea of an inclusionary participatory framework with improved communication between all stakeholders and better awareness of the context of the conflicts. In this light, the definition of precise goals, the extent to which the public can affect the outcome, and transparency of the process are essential to reach consensus among all the stakeholders about the use of a forest which is compatible with biodiversity conservation.

Qualitative methods for promoting participation, e.g. working groups, the Delphi technique and semistructured interviews (Pykäläinen, 2000), are often suitable for participatory planning. However, qualitative methods alone do not always adequately support decision-making. Participatory planning can be made more analytical, controlled and reliable by applying optimization (e.g. Kurttila and Pukkala, 2003), and tools of decision analysis, e.g. methods applying multi-attribute utility theory (Kangas, 1999; Pykäläinen et al., 1999). Such methods offer support for determining the forest management goals, creating efficient forest plan alternatives that minimize the utility losses of individual owners and comparing the alternative plans. This can make the results of the planning process more acceptable. Decision support of such type is also needed in landscape level forest planning (e.g. Kurttila, 2001).

\subsection{General framework of adaptive conflict manage- ment and forest planning}

Based on the above discussion, we have developed a general framework of adaptive conflict management emphasising communication among the parties and a 
participatory approach that should involve the monitoring of the conflict resolution outcomes (Fig. 2, see also Pykäläinen, 2000). This framework expands the 'basic conflict management framework' by Walker and Daniels (1997, p. 22-23), which includes three elements: strategy, implementation and assessment. In our framework, the main stakeholders (resource owners and managers) are the lynchpin in the process. Although it may be a difficult and time-consuming process to involve all stakeholders in the resolution process, it is a way of generating more democracy and the broadest public support ensuring the most acceptable outcome. Evaluation and research is needed to find out what the conflict is and how it could be solved. The conflict is then (hopefully) resolved in collaboration between scientists, other experts and the stakeholders. The outcome is monitored, and if a new conflict arises, the procedure is repeated. The indicators to be monitored may include those listed and discussed below (see Section 5).

\section{Identifying monitoring strategies}

It is difficult to unambiguously judge whether or not a conflict resolution process involving participatory procedures has been successful (Jeffers and Solberg, 1997) because the judgement depends on the definition of 'success', and is linked to the purpose of participation (Buchy and Hoverman, 2000). Furthermore, stakeholders' view on success may depend on whether they consider the participatory activity as an end in itself or as a means to an end (Buchy and Hoverman, 2000). For instance, in a disputed forest planning situation in Finland, one of the local stake- holders felt that the participatory process itself was successful, although the outcome of the process (i.e. the forestry plan) was not satisfactory (J. Niemelä, pers. observation).

We propose that monitoring the outcome is an integral component of conflict management process (Fig. 2), and should not serve as an end in itself, but as a feedback mechanism for improving the outcome and the process of conflict management. To make monitoring an integral part of the conflict resolution strategy, the following questions must be answered before monitoring begins (Niemelä, 2000): What is the goal of the monitoring to be undertaken? What are the indicators and methods to be used to achieve the goals? How are the data going to be analysed? How are the results going to be interpreted in terms of biological and socioeconomic implications? How are the results and interpretations going to be communicated to managers, decision makers and the public?

When monitoring the outcomes of a conflict management process, we propose the monitoring goals to be related to the three dimensions of conflicts (see Section 3.2).

\subsection{Substance}

Monitoring of the substance dimension aims at assessing the outcomes of the planning process for biodiversity, i.e. how the natural capital represented in forests is maintained after the actions agreed upon in the process have been carried out. Relatively simple core indicators could include the set of forest stand, landscape and national level indicators proposed by Larsson (2001).

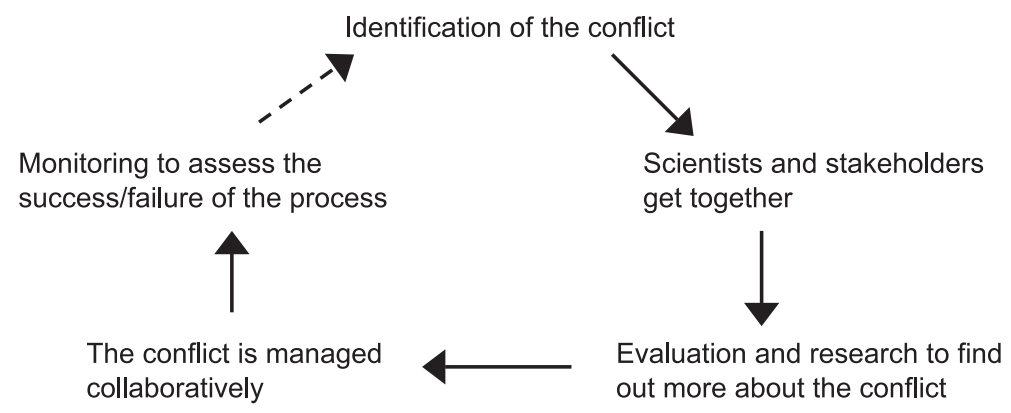

Fig. 2. General model of adaptive conflict management. 


\subsection{Procedure}

Monitoring the success of the process of conflict management deals with utilising the social capital in management organisations and local communities. Such assessment could include the following criteria and indicators:

Criterion 1. Performance of the process. Potential indicators: protected area acquired, funding spent, meetings held, and number of newspaper clippings reflecting media attention.

Criterion 2. Stakeholder opinions and views on the success of the process. Potential indicators: efficiency and effectiveness of the conflict management process, possibilities for stakeholder participation and engagement in the process, and degree of communication.

Criterion 3. Long-term management commitment to mitigation initiatives. Potential indicators: changes in strategies, policies, legislation, management procedure and process, planning and implementation, community and institutional participation, and degree of communication between institutions.

\subsection{Relationships}

Monitoring addressing relationships (i.e. 'how people behave') in the process of conflict management concerns the culture of individuals, organisations and society, and how they interact with each other. Assessment of human relationships in the conflict resolution process could include the following criteria and indicators:

Criterion 1. Culture of individuals. Potential indicators: how did the individuals involved perceive the conflict? How did the different stakeholders behave, communicate and collaborate in the conflict resolution process?

Criterion 2. Culture of organisations. Potential indicators: how was the conflict perceived by the organisations involved? How did the different organisations behave, communicate and collaborate in the conflict resolution process?

Criterion 3. Culture of society. Potential indicators: how was the conflict perceived by the society at large (e.g. others than those directly involved)? How did the conflict resolution strategy reflect the society at large (intense versus mild conflict, cooperative versus separative conflict, stable versus changing societal situation regarding the conflict area).

By integrating these criteria and indicators into a comprehensive monitoring system, and by adapting it to local conditions, one could acquire comparable monitoring information about various kinds of forest biodiversity related conflicts throughout Europe. As well as selecting indicators, one has to determine who undertakes the monitoring, who funds the monitoring and how the information derived from monitoring should be used. Conventionally, monitoring is done by outside experts using quantitative indicators with little help from local stakeholders. In a more inclusionary approach, local stakeholders could not only define the methodology, but also carry out the actual monitoring using their own specially defined indicators, adapted for their particular area and conflict (IDS, 1998). Theoretically, this approach should work well, especially in the long-term, but requires more research, a high level of input from experts in the preparatory stages and a clear definition of how the monitoring procedure is to evolve. In addition, it may benefit the long-term success of the resolved situation. At the same time, comparison of monitoring between conflicts would be more difficult.

\section{Conclusions: challenges of conflict management}

Identifying the nature of the conflict and why it has evolved into a conflict as well as assessing the stakeholder positions, and what stakeholders expect from the conflict resolution process are key assessments needed for a successful conflict management process. Stakeholders should also be made aware of the economic, scientific and social data relating to the issue in order to make the appropriate decisions. The specific 
role of scientists at this stage is to convey the scientific information in a clear, understandable way, avoiding using scientific jargon or being patronising. As a source of information, scientists should focus on the research most useful for stakeholders decided upon in discussions. The subsequent data and analysis should then be relayed to the stakeholders. The position of scientists can be made difficult, as they often have to be a combination of a source of information, stakeholder, and mediator. As each conflict differs from the next, so will the role of scientists. Whatever the conflict, the part they play should be determined early on in the process and be made clear to all stakeholders.

Partnerships can be a useful way of improving conflict resolution strategies (McNeely, 1995). They should, however, not be confused with forums that tend to just discuss and comment. Successful partnerships can provide access to new resources (revenue and skills), they stimulate creativity and sharing as well as develop synergies, common appreciation of the issues, opportunities and shared solutions.

In summary, this study has identified a wide range of conflicts between forest biodiversity conservation and various land-uses in Europe's forests. Measures taken to reduce the impact of human activities on biodiversity have rarely focussed on managing the conflict but have addressed the impact through, for instance, legislation to reduce pollution and the establishment of protected areas. While this approach is valuable, there is an increasing realisation that it is not enough (Stoll-Kleemann and O'Riordan, 2002). Protected areas, in particular, may have limited value if there is a failure to establish an adequately linked network of sites to protect biodiversity (e.g. Flemming, 1995). The threat of climate change means that even well established networks may fail to protect biodiversity in the future. In addition, the establishment of protected areas, such as the NATURA 2000 network, and other strategies to conserve biodiversity can be a source of conflicts (Stoll-Kleemann, 2001b). These and other problems have led to the concept of "Protecting Beyond the Protected" (Stoll-Kleemann and O'Riordan, 2002).

We conclude that conflicts between forest biodiversity protection and other land uses can be addressed through the involvement of stakeholders and a combination of natural and social science because biodiversity is both an ecological and a social phenomenon (O'Riordan, 2002). This is also true of monitoring the outcome of conflict management, which is probably better viewed as an integral part of conflict management rather than a separate activity. Monitoring of biodiversity will play an essential role in assessing the implementation of European policies and directives. Monitoring must also play an important role in the management of biodiversity-related conflicts, which although usually manifest at large geographical scales, tend to have more local origins. Although monitoring must include an assessment of the impact on conflict management on biodiversity, it must also include an assessment of the management process itself. An integral approach to monitoring the management of biodiversity-related conflicts is clearly needed.

\section{Acknowledgements}

The authors acknowledge the help of Linda Davies, Marco Lauteri, Maarten van Nederveen, Fiorella Villani and Barbu Ion in the preparation of this paper.

\section{References}

Altmoos, M., 1999. Systeme von Vorranggebieten für den Tierarten-, Biotop- und Prozeßschutz: Auswahlmethoden unter Einbeziehung von Habitatmodellen für Zielarten am Beispiel der Bergbaufolgelandschaft im Südraum Leipzig. UFZ-Bericht 18/ 1999 1-252.

Baeta-Neves, R., 1990. História florestal, aquícola e cinegética. MAPA, DGF, Lisboa.

Ball, J.B., 2001. Global forest resources: history and dynamics. The Forest Handbook. Blackwell Science, Oxford.

Bilgili, E., Goldammer, J., 2001. Fire in the Mediterranean basin: towards an interdisciplinary science programme. Proceedings of the XXI IUFRO Congress, Kuala Lumpur, vol. 1, pp. 45-54.

Buchy, M., Hoverman, S., 2000. Understanding public participation in forest planning: a review. Forest Policy and Economics 1, $15-25$.

Carlsson, M.M., Andersson, B., Dahlin, B., Sallnäs, O., 1998. Spatial patterns of habitat protection in areas with non-industrial private forestry-hypotheses and implications. Forest Ecology and Management 107, 203-211.

Daniels, S.E., Walker, G.B., 1997. Collaborative learning and land management conflict. In: Solberg, B., Miina, S. (Eds.), Conflict Management and Public Participation in Land Management, EFI Proceedings 14. European Forest Institute, Joensuu, Finland, pp. $37-60$.

FAO, 2001. Global forest assessment. FAO Forestry Paper, vol. 140. FAO, Rome. 
FAO, 2002. Law and Sustainable Development since Rio-Legal Trends in Agriculture and Natural Resource Management. FAO Legislative Study, vol. 73. FAO, Rome.

Flemming, S.P., 1995. Using metapopulation viability analysis as a tool for assessing and maintaining the ecological integrity of protected areas. In: Herman, T.B., Bondrup-Nielsen, S., Willison, J.H.M., Munro, N.W.P. (Eds.), Ecosystem Monitoring and Protected Areas. Science and Management of Protected Areas Association, Wolfville, Canada, pp. 59-67.

Folke, C., Carpenter, S., Elmqvist, T., Gunderson, L., Holling, C.S., Walker, B., Bengtsson, J., Berkes, F., Colding, J., Danell, K., Falkermann, M., Gordon, L., Kasperson, R., Kaursky, N., Kinzig, A., Levin, S., Maler, K.-G., Moberg, F., Ohlsson, L., Olsson, P., Ostrom, E., Reid, W., Rockstrom, J., Savenije, H., Svedin, U., 2002. Resilience and sustainable development: building adaptive capacity in a world of transformations. ICSU Series on Science for Sustainable Development, vol. 3. International Council for Science, Paris.

Gamborg, C., 2002. The acceptability of forest management practices: an analysis of ethical accounting and the ethical matrix. Forest Policy and Economics 4, 175-186.

Hellström, E., 2001. Conflict cultures-qualitative comparative analysis of environmental conflicts in forestry. Silva Fennica. Monographs 2, 1-109.

Hellström, E., Reunala, A., 1995. Forestry conflicts from the 1950s to 1983. Research Report 3. European Forest Institute, Joensuu, Finland.

IDS, 1998. Participatory monitoring and evaluation: learning from change. IDS Policy Briefing, issue 12, November. Institute of Development Studies, University of Sussex, UK.

Jeffers, J.N.R., Solberg, B., 1997. Future activities and research topics. In: Solberg, B., Miina, S. (Eds.), Conflict Management and Public Participation in Land Management, EFI Proceedings, vol. 14. European Forest Institute, Joensuu, Finland, pp. $327-329$.

Kajala, L., Warson, A.E., 1997. Recreation conflicts in wilderness: an international comparison with implications for conflict management research. In: Solberg, B., Miina, S. (Eds.), Conflict Management and Public Participation in Land Management, EFI Proceedings vol. 14. European Forest Institute, Joensuu, Finland, pp. 303-313.

Kangas, J., 1999. The analytic hierarchy process (AHP): standard version, forestry application and advances. In: Helles, F., Holten-Andersen, P., Wichman, L. (Eds.), Multiple Use of Forests and Other Natural Resources. Kluwer Academic Publishers, Dordrecht, pp. 96-105.

Kurttila, M., 2001. Methods for integrating ecological objectives into landscape-level planning of non-industrial private forestry. Doctoral dissertation. Faculty of Forestry, University of Joensuu.

Kurttila, M., Pukkala, T., 2003. Combining holding-level economic goals with spatial landscape-level goals in the planning of multiple ownership forestry. Landscape Ecology 18, 529-541.

Larsson, T.-B. (Ed.), 2001. Biodiversity Evaluation Tools for European Forests, Ecological Bulletins, vol. 50.

Lipson, E., 1949. The Economic History of England. Adam and Charles Black, London.
Maguire, L.A., Boiney, L.G., 1994. Resolving environmental disputes: a framework incorporating decision analyses and dispute resolution techniques. Journal of Environmental Management 42, 31-48.

Mahanty, S., Russell, D., 2002. High stakes: lessons from stakeholder groups in the biodiversity conservation network. Society and Natural Resources 15, 179-188.

Margules, C.R., Pressey, R.L., 2000. Systematic conservation planning. Nature 405, 243-253.

Matthews, J.D., 1989. Silvicultural Systems. Oxford Science Publications, Oxford.

Mayer, P., 2000. Hot spot: forest policy in Europe: achievements of the MCPFE and challenges ahead. Forest Policy and Economics $1,177-185$.

McCool, S.F., Guthrie, K., Smith, J.K., 2000. Building consensus: legitimate hope or seductive paradox? USDA Forest Service Rocky Mountain Research Station Research Paper.

McNeely, J.A., 1995. Expanding Partnerships in Conservation. Island Press, Washington, DC.

Niemelä, J., 2000. Biodiversity monitoring for decision-making. Annales Zoologici Fennici 37, 307-317.

O'Riordan, T., 2002. Protecting beyond the protected. In: O'Riordan, T., Stoll-Kleemann, S. (Eds.), Biodiversity, Sustainability and Human Communities: Protecting Beyond the Protected. Cambridge Univ. Press, Cambridge, pp. 3-29.

Perlin, J., 1989. A Forest Journey: the Role of Wood in the Development of Civilization. Harvard Univ. Press, Cambridge, MA.

Priscoli, J.D., 1997. Participation and conflict management in natural resources decision-making. In: Solberg, B., Miina, S. (Eds.), Conflict Management and Public Participation in Land Management, EFI Proceedings, vol. 14. European Forest Institute, Joensuu, Finland, pp. 61-87.

Prodon, R., Fons, R., Athias-Binche, F., 1987. The impact of fire on animal communities in Mediterranean areas. In: Trabaud, L. (Ed.), The Role of Fire in Ecological Systems. SPB Academic Publishing, Den Haag, pp. 121-157.

Pukkala, T., Kangas, J., Kniivilä, M., Tiainen, A.-M., 1997. Integrating forest level and compartment level indices of species diversity with numerical forest planning. Silva Fennica 31, 417-429.

Pykäläinen, J., 2000. Defining forest owners' forest management goals by means of a thematic interview in interactive forest planning. Silva Fennica 34, 47-59.

Pykäläinen, J., Kangas, J., Loikkanen, T., 1999. Interactive decision analysis in participatory strategic forest planning: experiences from state owned boreal forests. Journal of Forest Economics 5, 341-364.

Rantala, T., Primmer, E., 2003. Value positions based on forest policy stakeholders' rhetoric in Finland. Environmental Science and Policy 6, 205-216.

Schama, S., 1996. Landscape and Memory. Harper Collins, London.

Stoll-Kleemann, S., 2001a. Barriers to nature conservation in Germany: a model explaining opposition to protected areas. Journal of Environmental Psychology 21, 369-385.

Stoll-Kleemann, S., 2001b. Opposition to the designation of protected areas in Germany. Journal of Environmental Planning and Management 44, 111-130. 
Stoll-Kleemann, S., O'Riordan, T., 2002. Enhancing biodiversity and humanity. In: O'Riordan, T., Stoll-Kleemann, S. (Eds.), Biodiversity, Sustainability and Human Communities: Protecting Beyond the Protected. Cambridge Univ. Press, Cambridge, pp. $295-310$.

Tikka, P., 2003. Conservation contracts in habitat protection in southern Finland. Environmental Science and Policy 6, $271-278$

Tikka, P.M., Kauppi, P. (Eds.), 2003. Protecting nature on private land-from conflicts to agreements, Environmental Science and Policy, vol. 6, pp. 193-328.

Trabaud, L., Prodon, R. (Eds.), 1993. Fire in Mediterranean Ecosystems, Ecosystems Research Report, vol. 5. Commission of the European Communities, Brussels.
Walker, G.B., Daniels, S.E., 1997. Foundations of natural resource conflict: conflict theory and public policy. In: Solberg, B., Miina, S. (Eds.), Conflict Management and Public Participation in Land Management. EFI Proceedings, vol. 14. European Forest Institute, Joensuu, Finland, pp. 13-36.

Weber, M., Schönenberger, W., Weiss, G. (Eds), 2002. New paradigms in management of forests in mountainous regions. Final report to the Concerted Action "Multifunctional Forest Management-Evaluation of Policy and Silvicultural Means for Mountainous Regions". Verlag Dr. Kessel, Remagen. 